\title{
Bone single photon emission computed tomography with computed tomography disclosing chronic uterine perforation with intrauterine device migration into the anterior wall of the bladder: a case report
}

\author{
David Morland ${ }^{1}$, Carole Mathelin ${ }^{2}$, Arnaud Wattiez ${ }^{3}$ and Izzie Jacques Namer ${ }^{1,4^{*}}$
}

\begin{abstract}
Introduction: Extraosseous uptake of ${ }^{99 \mathrm{~m}} \mathrm{Tc}$-hydroxymethylene diphosphonate is a common situation of variable clinical relevance.

Case presentation: A 52-year-old Caucasian woman presented to our department for breast cancer staging. A ${ }^{99 m}$ Tc-hydroxymethylene diphosphonate bone scan was performed and showed focal pelvic hyperfixation that disclosed intrauterine device migration into the anterior wall of the bladder on single photon emission computed tomography with computed tomography.

Conclusion: This observation confirms the major role of single photon emission computed tomography with computed tomography in achieving an exact diagnosis.
\end{abstract}

Keywords: Intrauterine device complication, Bone scan, SPECT/CT

\section{Introduction}

Extraosseous soft tissue uptake of ${ }^{99 \mathrm{~m}} \mathrm{Tc}$-hydroxymethylene diphosphonate (HMDP) is a common situation but of variable clinical relevance. These lesions are often encountered as incidental findings and may sometimes change the therapeutic approach for certain patients. The intrauterine device (IUD) is a frequently used and effective contraceptive method. Complications after IUD insertion, such as chronic uterine perforation, are rare but serious.

We present a case of a patient with chronic uterine perforation with IUD migration into the anterior wall of the bladder, discovered on bone single photon emission

\footnotetext{
* Correspondence: Izzie.Jacques.NAMER@chru-strasbourg.fr

'Service de Biophysique et Médecine Nucléaire, Hôpitaux Universitaires de Strasbourg, Hôpital de Hautepierre, 1 avenue Molière, 67098, Strasbourg, Cedex 09, France

${ }^{4}$ ICUBE, Université de Strasbourg/CNRS UMR 7357, FMTS - Faculté de Médecine, 4 rue Kirschleger, 67085, Strasbourg, Cedex, France

Full list of author information is available at the end of the article
}

computed tomography with computed tomography (SPECT/CT).

\section{Case presentation}

A 52-year-old Caucasian woman was referred to the Breast Diseases Center of the Strasbourg University Hospitals for the management of a bifocal infiltrating lobular carcinoma located in the upper outer quadrant of her right breast. She was multiparous (three children) and had been menopausal for one year. Her medical history showed no relevant data except for a Cesarian section. An IUD had been inserted after the last pregnancy 12 years ago. Another hormonal IUD had been inserted five years ago and removed before her breast surgery. A recent clinical pelvic examination had not revealed an IUD string. After neoadjuvant chemotherapy, she underwent a lumpectomy and axillary clearance. The histological examination revealed a residual focus of lobular carcinoma (pT1c) and each of the 30 axillary lymph nodes removed was negative. Breast surgery was 
followed by locoregional radiotherapy and hormonal therapy. A chest X-ray and an abdominal ultrasound for cancer staging were performed and revealed no metastasis. Cancer antigen (CA 15-3) showed a normal value $(23 \mathrm{U} / \mathrm{ml})$.

A bone scan for cancer staging was also performed in November 2012 (Figure 1). It showed symmetrical and homogeneous uptake of the tracer compound in bone structures. However, bone scintigraphy disclosed a focal pelvic hyperfixation in her bladder area on anterior incidence. SPECT/CT was performed and showed a mislocated IUD in the anterior vesical wall (Figure 2) corresponding to focal ${ }^{99} \mathrm{~m}$ Tc-HMDP hyperfixation due to a probable inflammatory granuloma surrounding the IUD.

\section{Discussion}

Uterine perforation is a rare yet serious event and occurs at a rate between 1 out of 10,000 and 1 out of 350 IUD insertions [1]. In contrast to acute uterine perforation, which is often symptomatic and occurs during insertion, chronic perforation may occur at any time and is generally asymptomatic [2]. Several risk factors have been identified and can be classified into three categories [2-4]: (i) uterine factors: myometrial weakness (multiparity, Cesarean section), pronounced retro- or anteversion, uterine hypoplasia, insertion in the early post-partum period; (ii) IUD insertion technique including operator experience; and (iii) IUD type: perforation might be more frequent with copper IUDs [1].

Transuterine migration consists of two steps: uterine infraction and uterine migration. Spontaneous uterine contractions and local inflammation are found in these cases.

Migration usually occurs to the peritoneal cavity or to adjacent neighboring organs. In a review of the literature, we found 140 cases of intra-abdominal migration and 50 cases of intravesical migration of which 42.9 percent presented with lithiasis $[2,4,5]$. Indeed, calcification may occur when the IUD migrates into the bladder. However, there is no correlation between calcification and time spent in the bladder $[3,4]$.

Mechanisms of extraosseous fixation are multiple and often intricate. When lesions contain microcalcification, the mechanism for increased accumulation is considered similar to that which occurs in normal bone: chemisorption onto calcium [6]. In injured tissue, intracellular calcium influx and calcium precipitation are responsible for the fixation.

Several diagnoses may be suspected when a pelvic hyperfixation occurs on a bone scan [7-9]. Typical causes are fourfold:

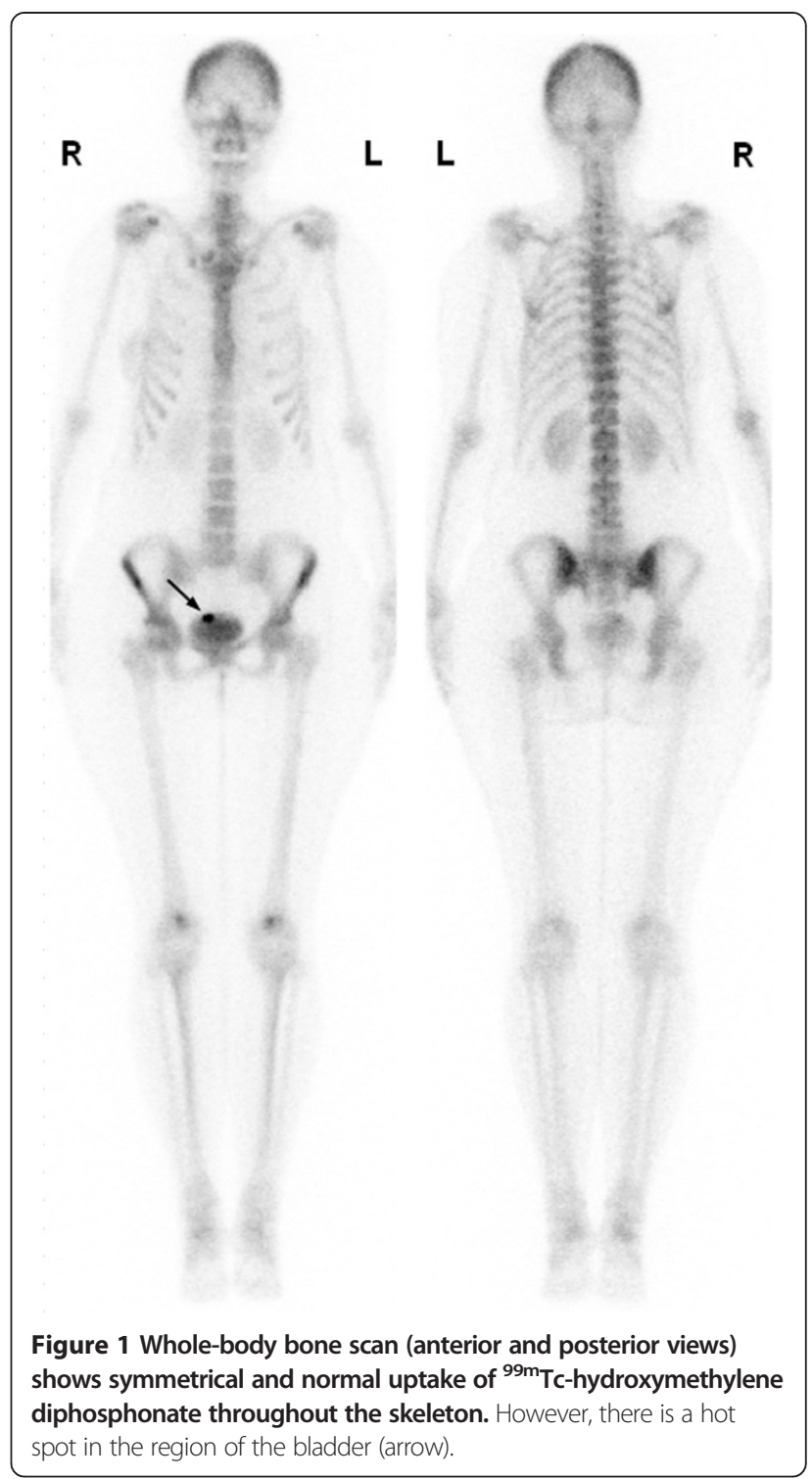

- Focal hyperfixation due to urinary tract pathology such as vesical diverticulum, calcified foreign body granuloma, bilharziasis or tuberculosis;

- Genital tract pathology: calcified uterine fibroid, endometrial tumor and a variety of ovarian tumors;

- Peritoneal metastasis;

- General causes: postradiation lesions, hematoma.

\section{Conclusions}

IUD migration is a rare cause of pelvic extraosseous accumulation of bone radiotracers, which should be kept in mind.

This observation also confirms the major role played by SPECT/CT in achieving an exact diagnosis. 


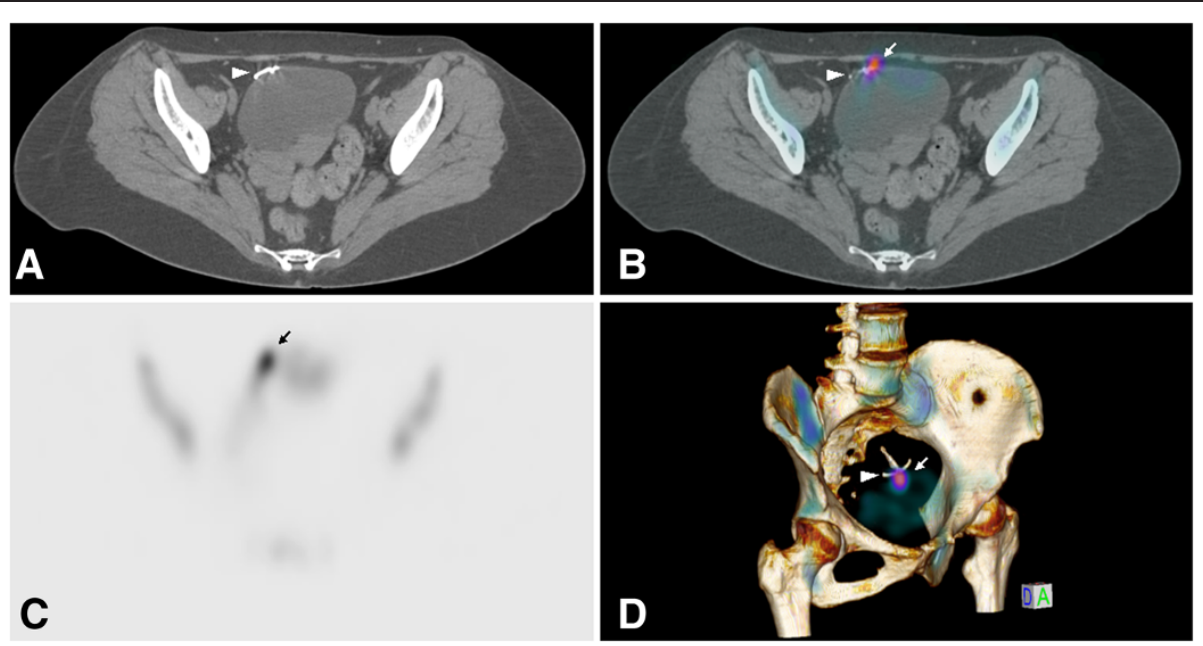

Figure 2 Pelvic single photon emission computed tomography with computed tomography reveals a focal ${ }^{99 m}$ Tc-hydroxymethylene diphosphonate hyperfixation (plain arrow) centered at a mislocated intrauterine device (arrow head) in the anterior vesical wall. (A) Axial computed tomography slice. (B) Axial single photon emission computed tomography. (C) Axial single photon emission computed tomography with computed tomography. (D) Volume-rendering single photon emission computed tomography with computed tomography.

\section{Abbreviations}

SPECT/CT: single photon emission computed tomography with computed tomography; IUD: intrauterine device.

\section{Competing interests}

The authors declare that they have no competing interests.

\section{Authors' contributions}

DM and IJN diagnosed and drafted the manuscript. CM and AW followed up and managed the patient. All authors read and approved the final manuscript.

\section{Consent}

Written informed consent was obtained from the patient for publication of this case report and accompanying images. A copy of the written consent is available for review by the Editor-in-Chief of this journal.

\section{Author details}

'Service de Biophysique et Médecine Nucléaire, Hôpitaux Universitaires de Strasbourg, Hôpital de Hautepierre, 1 avenue Molière, 67098, Strasbourg, Cedex 09, France. Unité de Sénologie, Pôle de Gynécologie-Obstétrique, Hôpitaux Universitaires de Strasbourg, Hôpital de Hautepierre, 1 avenue Molière, 67098, Strasbourg, Cedex 09, France. ${ }^{3}$ Service de Gynécologie, Pôle de Gynécologie-Obstétrique, Hôpitaux Universitaires de Strasbourg, Hôpital de Hautepierre, 1 avenue Molière, 67098, Strasbourg, Cedex 09, France. ${ }^{4}$ ICUBE, Université de Strasbourg/CNRS UMR 7357, FMTS - Faculté de Médecine, 4 rue Kirschleger, 67085, Strasbourg, Cedex, France.

Received: 20 February 2013 Accepted: 21 March 2013

Published: 10 June 2013

\section{References}

1. Ceccato V, Boileau A, Roblin M, Tariel D, Bon D, Estrade V: Migration intravésicale d'un dispositif intra-utérin. Stratégies d'exploration et modalités thérapeutiques. Prog Urol 2007, 17:256-259.

2. Ech-Cherif El Kettani N, Dafiri R: Imagerie de la migration des dispositifs intra-utérins. Feuil Radiol 2007, 47:159-166.

3. El Ammari JE, El Fassi MJ, Farih MH: Migration intravésicale des dispositifs intra-utérins. Presse Med 2009, 38:1185-1188.

4. Haouas N, Sahraoui W, Youssef A, Thabet I, Mosbah AT: Migration intra-v ésicale de dispositif intra-utérin compliquée de lithiase. J Gynecol Obstet Biol Reprod 2006, 35:288-292
5. Bacha K, Ben Amna M, Ben Hassine L: Dispositif intra-utérin migré dans la vessie. Prog Urol 2011, 11:1289-1291.

6. Mihara F, Nakayama C, Nakata H, Sakakibara N, Zeze F, Kitahara J, Sanefuji H: 99mTc-methylene diphosphonate uptake by ossifications and calcifications of non-osseous metastatic tumors. Eur J NuCl Med 1986, 12:413-416

7. Elgazzar AH: Diagnosis of soft tissue calcification. In Orthopedic Nuclear Medicine. Edited by Elgazzar AH. Berlin, Heidelberg: Springer-Verlag; 2004:197-210.

8. Beres RA, Patel N, Krasnow AZ, Isitman AT, Hellman RS, Veluvolu P, Patillo RS, Collier BD: Concentration of Tc-99m MDP in ovarian carcinoma and its soft tissue metastases. Clin Nucl Med 1991, 16:550-552.

9. Goldfarb CR, Ongseng F, Kuhn M, Metzger T: Non-skeletal accumulation of bone seeking agents: pelvis. Semin NuCl Med 1988, 18:159-161.

\section{doi:10.1186/1752-1947-7-154}

Cite this article as: Morland et al:: Bone single photon emission computed tomography with computed tomography disclosing chronic uterine perforation with intrauterine device migration into the anterior wall of the bladder: a case report. Journal of Medical Case Reports 2013 7:154.

\section{Submit your next manuscript to BioMed Central and take full advantage of:}

- Convenient online submission

- Thorough peer review

- No space constraints or color figure charges

- Immediate publication on acceptance

- Inclusion in PubMed, CAS, Scopus and Google Scholar

- Research which is freely available for redistribution
Biomed Central 